\title{
Somatic-Respiratory Reflex and Onset of Regular Breathing Movements in the Lamb Fetus in Utero
}

\author{
SALVATORE CONDORELLI AND EMILE M. SCARPELLI ${ }^{134}$ \\ WITH THE TECHNICAL ASSISTANCE OF FRANKLIN A. TAYLOR
}

Pulmonary Division, Department of Pediatrics, Albert Einstein College of Medicine, Bronx, New York, USA

\section{Extract}

Breathing activity of six mature lamb fetuses $1>135$ days of gestation) in utero was monitored from recordings of intraesophageal pressure, intratracheal pressure, and tracheal circumference from a mercury strain gauge before, during, and after stimulation of the central end of a cut sciatic nerve. Stimuli were either low (0.5-2.0 cps) or high ( $66 \mathrm{cps}$ ) frequency, $6-15-\mathrm{V}$ square wave pulses of $0.6-1.25$ msec duration. The fetuses remained in utero throughout the experiments in which ambient temperature, $\mathrm{paO}_{2}, \mathrm{paCO}_{2}$, arterial $\mathrm{pH}$, mechanical stimulation, and spontaneous respiratory center activity could be ruled out as primary stimuli of the breathing movements observed. In one-third of the trials a "somatic-respiratory reflex" was elicited in which breathing coincided with the period of stimulation: in over $85 \%$ of these trials with low frequency stimulation, breathing movements were synchronous with the stimuli; in the rest the synchrony was broken during the period of stimulation. In two-thirds of the trials the "reflex" response was followed by spontaneous regular breathing movements ("onset of regular breathing") which continued for $1 \mathrm{~min}$ to $2 \mathrm{hr} 30$ min after the stimulation was stopped. Thiopental administration to the ewe $(5 \mathrm{mg} / \mathrm{kg})$ seemed to depress respiratory responsivity for about $60 \mathrm{~min}$. Changes of tracheal circumference reflected both transmural pressure gradients and possibly also rhythmic vagal activity associated with breathing.

\section{Speculation}

The characteristics of the electrical stimuli have been shown in other species to include $\gamma$ and $\delta$ group $A$ and group $C$ afferents, which normally transmit pain, temperature, pressure, touch, and position. Thus, our studies support the idea that somatic sensory stimuli can produce regular breathing at birth. Indeed it is shown that these stimuli are effective even in the absence of other changes in homeostasis that may be associated with the onset of breathing. Since regular breathing movements may be induced consistently, the experimental preparation is ideal for future studies of maturation of the control of breathing during gestation. The "respiratory reflex" that has been described seems to fit the basic definition; this has permitted the formulation of a working hypothesis for the activation and recruitment of quiescent respiratory center neurons, i.e., for the genesis of respiratory center activity.

In a previous study it was shown that electrical stimulation of afferent fibers of peripheral somatic nerves produces a breathing response in the lamb fetus (12). We have now carried this line of research to the mature fetal lamb in utero in which breathing movements have been monitored directly. The present report of these studies confirms and extends the previous findings and, in addition, reveals the existence of a peripheral nerve-respiratory reflex and the generation of sustained spontaneous regular breathing movements in the fetus before birth. The electrical impulses used (which for the lamb fetus must be considered as producing nonspecific somatic afferent stimulation) stimulate afferent $\gamma$ and $\delta$ group $A$ and group $C$ fibers of peripheral nerves in other adult species $(7,24)$, i.e., fibers that normally transmit pain, temperature, pressure, touch, and position. Thus support is given to those reports that suggest that somatic sensory stimuli may produce regular breathing at birth (25); indeed it is shown that these stimuli may be effective even in the absence of any of the other disruptions of fetal homeostasis that normally accompany the birth process. Whereas the regular breathing movements that were induced by somatic afferent stimulation resemble those of the neonate, they differ from the naturally spontaneous but irregular breathing movements of the fetus that have been reported by other investigators $(2,17,18,23)$.

\section{METHODS}

Anesthesia was induced in six pregnant ewes $(>135$ days of gestation) with sodium thiopental, $5 \mathrm{mg} / \mathrm{kg}$ i.v., and maintained as needed with $\mathrm{N}_{2} \mathrm{O}: \mathrm{O}_{2}, 2: 1-3: 1$. The ewe was tracheotomized and ventilation was controlled with an Air Shields volume-cycled ventilator (30): maternal $\mathrm{paO}_{2}>90 \mathrm{~mm} \mathrm{Hg}$; $\mathrm{paCO}_{2}$ between 35 and $40 \mathrm{~mm} \mathrm{Hg}$; and arterial $\mathrm{pH}$ between 7.38 and 7.42. The uterus was herniated through a paramedian incision of the abdominal wall and the neck of the fetus was incised and marsupialized to the uterine wall by methods described previously $(12,26)$. Virtually no amniotic fluid was lost as the fetus remained within the uterus throughout the period of preparation and experimentation.

A polyethylene catheter was passed through the fetal neck incision into the carotid artery and advanced to the ascending aorta; an esophageal balloon was placed in the upper to middle third of the esophagus; and a glass cannula was inserted into the trachea. The dead space of the cannula was allowed to fill spontaneously with fetal pulmonary fluid so that no air was introduced into the lung. A mercury strain gauge was placed around the trachea and sutured to the serosal surface anteriorly (27) two to three intercartilagenous spaces below the glass cannula A polyethelene catheter was passed through the uterine wall directly into the amniotic cavity of two of the fetuses.

A uterine horn was incised and through it a lower limb of the fetus was exteriorized without loss of amniotic fluid. The uterine wall was sutured to the skin of the hindlimb, an incision was made at the level of the femoral triangle, and a platinum electrode-tipped catheter was inserted into the femoral artery and advanced to the descending aorta below the renal artery.

The sciatic nerve was exposed, severed, and covered with paraffinated gauze. A Grass stimulator (31) was used to stimulate the central end of the cut sciatic nerve. Stimuli were either high frequency $(66 \mathrm{cps})$ or low frequency $(0.5-2 \mathrm{cps})$, square wave, 0.6 to $1.25 \mathrm{msec}$, and 6 to $15 \mathrm{~V}$, according to the method of Colle and Gybels (7) and Khayutin (22).

Aortic pressure, intraesophageal pressure (IEP), intratracheal pressure (ITP), tracheal circumference from the mercury strain gauge, output from the platinum electrode (ECG or stimulus artifact), and amniotic fluid pressure were recorded on a specially designed Physiograph VI 10-channel polygraph. 
The preparative procedures were completed within $1 \mathrm{hr}$, at which time stimulation of the central end of the sciatic nerve was begun. Low frequency stimuli were used $67 \%$ of the time, starting at $6 \mathrm{~V}$ and increasing to $15 \mathrm{~V}$ until a response was elicited. High frequency stimuli, within the same voltage range, were interspersed regularly. The period of stimulation was $10-75 \mathrm{sec}$. Stimulation with $15-\mathrm{V}, 1.05-1.25-\mathrm{msec}$, square wave pulses produced a response in each fetus; some fetuses responded to lower voltages. The experimental trials are summarized in Table 1.

Aortic blood samples, which were obtained every $25 \mathrm{~min}$ or less, indicated that the fetuses were in a stable and steady state throughout the course of the experiments, including the periods of breathing, viz., $\mathrm{paO}_{2} 30-35 \mathrm{~mm} \mathrm{Hg}$; $\mathrm{paCO}_{2} 38-42 \mathrm{~mm} \mathrm{Hg}$; arterial $\mathrm{pH}$ between 7.26 and 7.36. Only one fetus had $\mathrm{pH}<7.3$; the responses of this fetus were not different from the others.

\section{RESULTS}

In most of the experiments ITP was recorded from a transducer connected to the end of the tracheal cannula, so that breathing movements were made against a closed airway.

\section{SPONTANEOUS BREATHING MOVEMENTS}

No spontaneous breathing movements were recorded for about $60 \mathrm{~min}$ after the induction of anesthesia with sodium thiopental, nor was it possible to elicit breathing by stimulation of the sciatic nerve during this time. Thereafter, when not specifically stimulated, the fetus made spontaneous breathing efforts which were irregular and included movements in which either high negative pressures ("sighs") or positive pressures ("grunts") were produced. The sighs and grunts occurred at a frequency of about $1-3 / \mathrm{hr}$ and appeared either as single or as a series of 2-3 breathing efforts.

\section{SOMATIC-RESPIRATORY REFLEX}

After $60 \mathrm{~min}$, breathing movements were induced consistently in all fetuses by stimulation of the sciatic nerve with pulses of $15 \mathrm{~V}$, $1.05-1.25 \mathrm{msec}$ duration. Two fetuses also responded to $6 \mathrm{~V}$ and two to $10 \mathrm{~V}$. One-third of all responses coincided with the period of stimulation, i.e., breathing started and ended at or close to the onset and cessation of stimulation. These responses, which we have called "the somatic-respiratory reflex," are described in this section.

The typical reflex response to low frequency stimulation is shown in Figures 1 and 2: characteristically $(I)$ a shallow or weak inspiratory effort is made with the first stimulus pulse, (2) negative inspiratory pressures increase as stimulation is continued, (3) breathing frequency equals stimulation frequency, (4) the onset of

Table 1. Summary of experiments ${ }^{1}$

\begin{tabular}{|c|c|c|}
\hline & $\begin{array}{l}\text { Low frequency } \\
\text { stimulation }\end{array}$ & $\begin{array}{l}\text { High frequency } \\
\text { stimulation }\end{array}$ \\
\hline \multicolumn{3}{|l|}{ Respiratory reflex } \\
\hline Number of trials & 20 & 10 \\
\hline $\begin{array}{l}\text { Breathing frequency } \\
\text { (breaths } / \mathrm{min} \text { ) }\end{array}$ & $\begin{array}{l}\text { Synchronous } \\
\qquad(>85 \%)\end{array}$ & $40-75$ \\
\hline \multicolumn{3}{|l|}{ Onset of regular breathing } \\
\hline Number of trials & 40 & 20 \\
\hline $\begin{array}{l}\text { Breathing frequency; sponteneous } \\
\text { (breaths/min) }\end{array}$ & $22-45$ & $20-45$ \\
\hline $\begin{array}{l}\text { Duration of spontaneous breathing } \\
\text { (min) }\end{array}$ & $1-98$ & $1-150$ \\
\hline $\begin{array}{l}\text { Latency; onset stimulation to first } \\
\text { response (sec) }\end{array}$ & $\begin{array}{l}0(75 \%) \\
<20(25 \%)\end{array}$ & $\begin{array}{c}0(75 \%) \\
<20(20 \%) \\
\text { After stimulation } \\
\text { period }(5 \%)\end{array}$ \\
\hline
\end{tabular}

${ }^{1}$ Number of mature fetuses, 6 ; trials per fetus, 15; total number of trials, 90; percentage responding to stimulation, 100\%; type response: "reflex" $33 \%$; “onset breathing," $67 \%$.

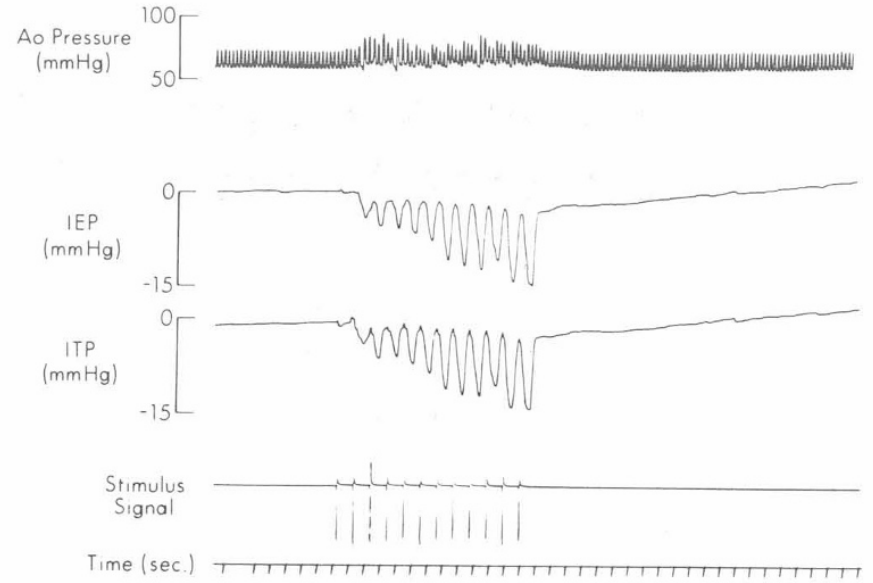

Fig. 1. Fetal aortic $(A O)$ pressure, intraesophageal pressure $(I E P)$, and intratracheal pressure (ITP) during low frequency stimulation (15-V, $1.05-\mathrm{msec}$ pulses at $1.0 \mathrm{cps}$ ) of the central end of the cut sciatic nerve.
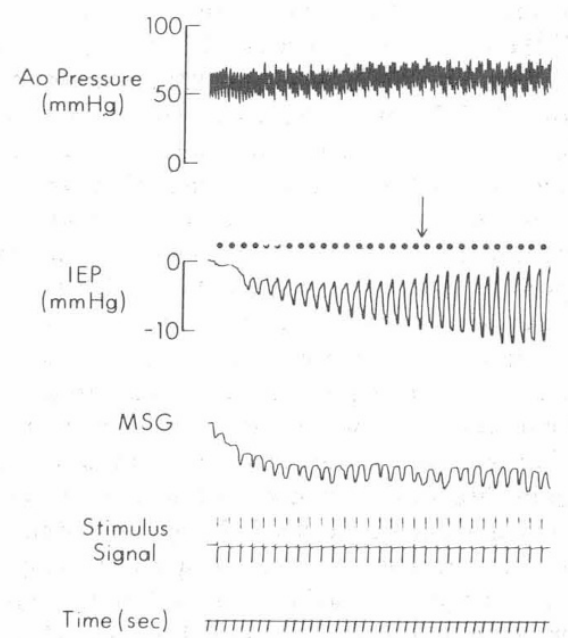

Fig. 2. Fetal aortic $(A O)$ pressure, intraesophageal pressure $(I E P)$, and tracheal circumference as recorded from the mercury strain gauge $(M S G)$. Downward deflections from MSG indicate decreasing circumference and upward deflections indicate increasing circumference. Low frequency stimulation $(15-\mathrm{V}, 1.25-\mathrm{msec}$ pulses at $0.5 \mathrm{cps})$ of the central end of the cut sciatic nerve. Breathing movements to the left of the arrow are synchronous with stimulus pulses; those to the right of the arrow are at a faster frequency.

each breathing cycle coincides with a single stimulus, and (5) breathing movements stop when stimulation is stopped. In addition, although the frequency of breathing movements was synchronous with the frequency of stimulation in over $85 \%$ of the trials, this synchrony was sometimes broken as breathing rate came to exceed stimulation rate (Fig. 2).

Tracheal circumference, as recorded from the mercury strain gauge, decreased during each inspiration and increased during expiration (Fig. 2). Aortic pressure waves tended to follow the changes in IEP and ITP. The maximum negative IEP and ITP during these periods ranged from -5 to $-20 \mathrm{~mm} \mathrm{Hg}$.

A typical reflex response to high frequency stimulation is shown in Figure 3, wherein a sustained, relatively deep initial inspiratory effort was followed by regular breathing movements at a frequency that varied from 40 to $75 / \mathrm{min}$ among the different trials. Characteristically, regular breathing was maintained only during the period of high frequency stimulation.

\section{INDUCTION OF SPONTANEOUS REGULAR BREATHING}

In two-thirds of the trials of low and high frequency stimulation of the sciatic nerve, spontaneous regular breathing movements continued after stimulation was stopped. The duration of post- 
stimulation spontaneous breathing, at a frequency of $20-45 / \mathrm{min}$. varied among trials from $1 \mathrm{~min}$ to $2 \mathrm{hr} 30 \mathrm{~min}$. A typical response, which we have called "the onset of regular breathing," is shown in Figure 4.

The onset of regular breathing response to low frequency stimu- lation may be characterized as follows: $(l)$ initial inspiratory efforts, during the period of stimulation, progressively increase to a maximal end-inspiratory pressure of -8 to more than $-20 \mathrm{~mm}$ $\mathrm{Hg}$; (2) when stimulation is stopped breathing continues regularly and spontaneously at a somewhat slower frequency than during

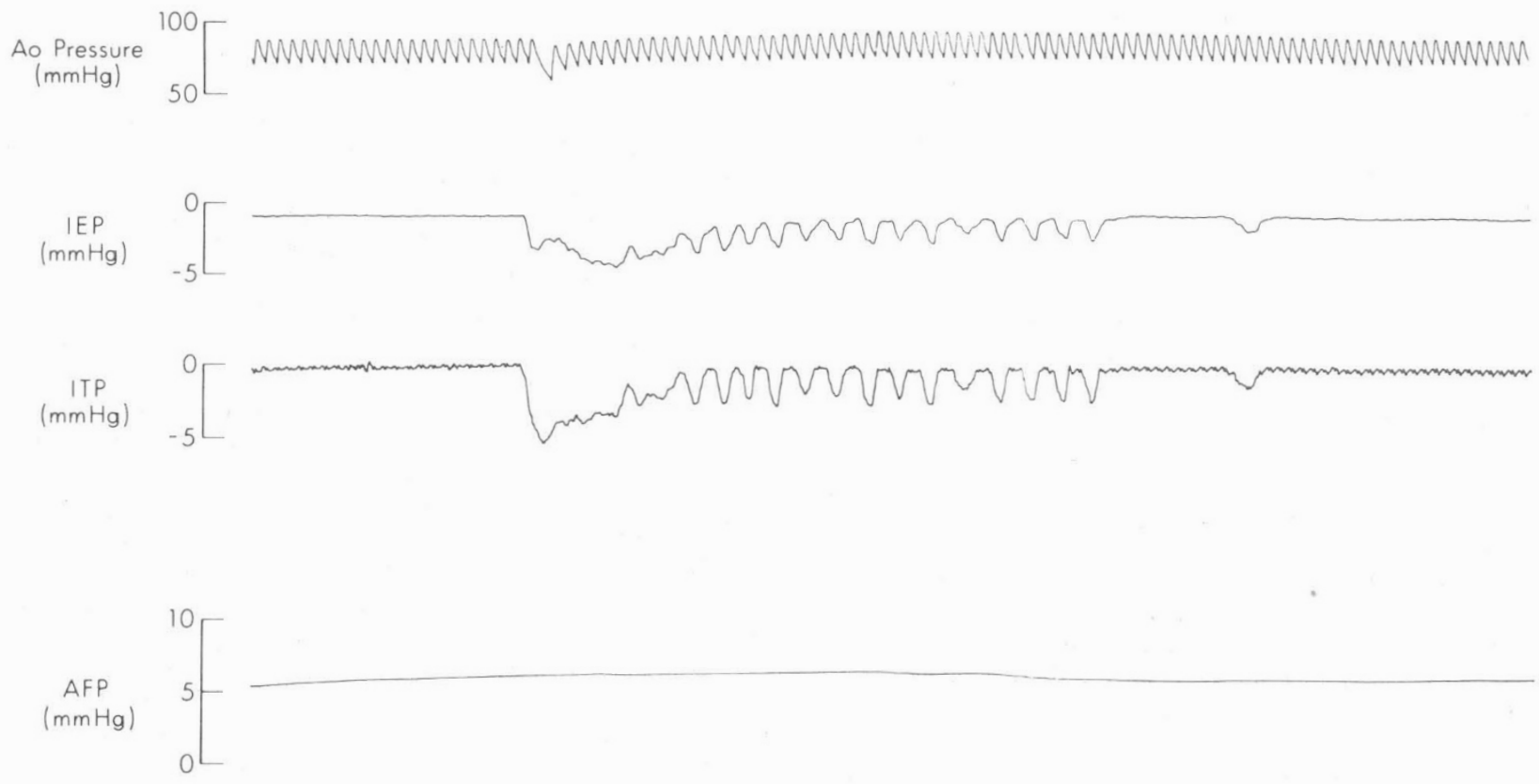

Stimulus Signal

Time $(\mathrm{sec})$

Fig. 3. Fetal aortic $(A o)$ pressure, intraesophageal pressure $(I E P)$, intratracheal pressure $(I T P)$, and amniotic fluid pressure $(A F P)$ durıng high frequency stimulation $(15-\mathrm{V}, 1.05-\mathrm{msec}$ pulses at $66 \mathrm{cps})$ of the central end of the cut sciatic nerve.
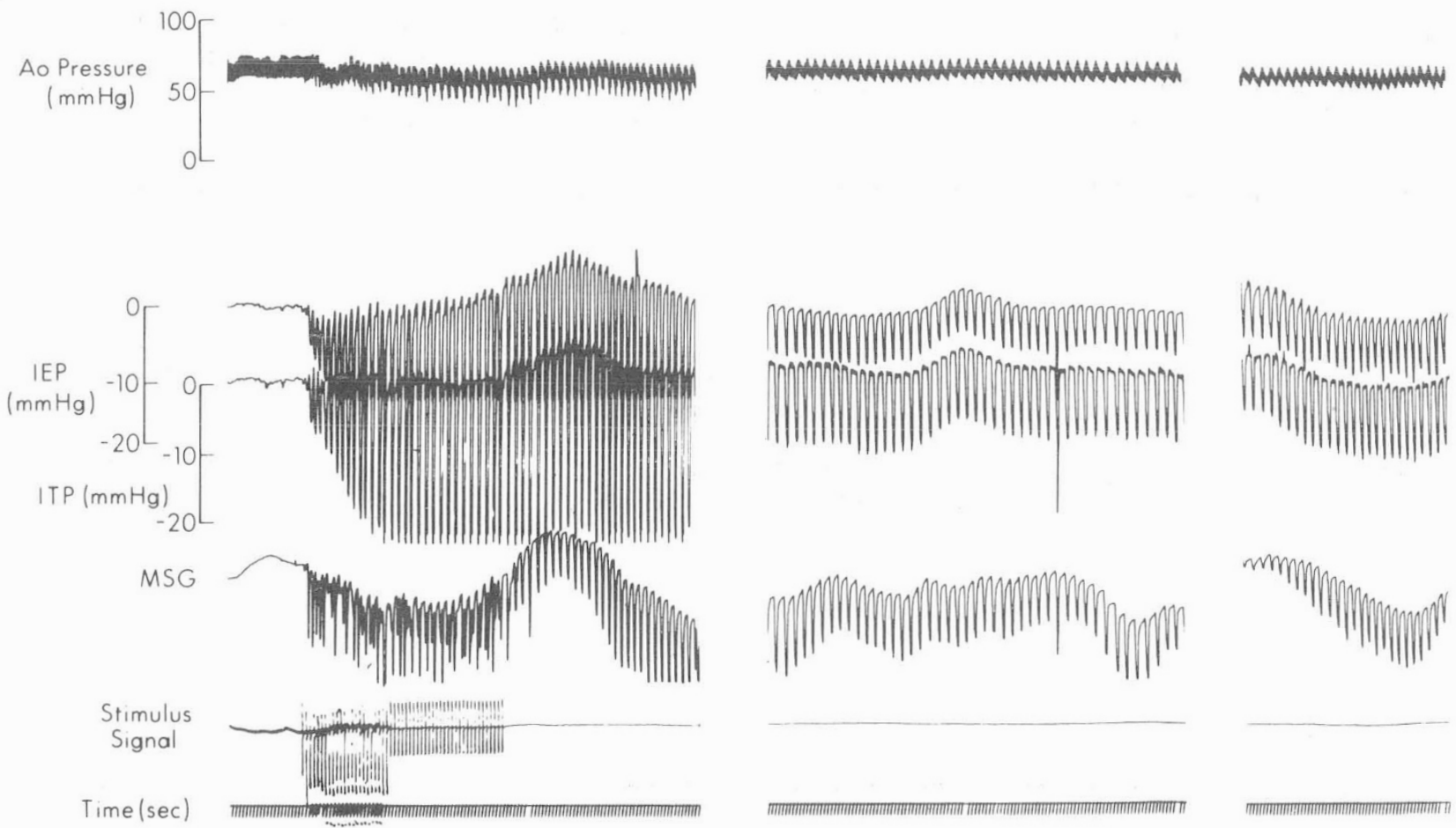

Fig. 4. Fetal aortic $(A O)$ pressure, intraesophageal pressure $(I E P)$, intratracheal pressure $(I T P)$, and tracheal circumference from the mercury strain gauge $(M S G)$. Response to low frequency stimulation $(15-\mathrm{V}, 1.25$-msec pulses at $1.0 \mathrm{cps})$ is followed by continued regular spontaneous breathing after stimulation is stopped. Left panel: stimulation and immediate poststimulation period; middle and right panels: continued regular breathing $1 \mathrm{hr}$ and $2 \mathrm{hr} 30$ min after cessation of stimulation, respectively. Note: small fluctuations of MSG in right panel are due to mechanical limitation of the recording pen; IEP and ITP negative deflections in the left panel were limited for the same reason. 
the period of stimulation; and (3) spontaneous regular breathing continues for a variable period, then either stops abruptly or rapidly as frequency and pressures diminish progressively.

The onset of regular breathing response to high frequency stimulation is shown in Figure 5. Generally, the first inspiratory effort was relatively strong and sustained before regular breathing movements were established during the period of stimulation. End-expiratory IEP and ITP tended to be lower than the respective pressures during prestimulation apnea. When high frequency stimulation was stopped, spontaneous regular breathing efforts continued but at a slower frequency than during the period of stimulation. The period of spontaneous regular breathing ended either abruptly or rapidly as described above.

\section{CORRELATIVE OBSERVATIONS}

Tracheal circumference, as determined from the mercury strain gauge, decreased during each inspiratory effort, then returned to approximately the preinspiratory ("resting") level at end-expiration (Figs. 2 and 4). These breath-by-breath changes in circumference often were superimposed upon slow periodic variations of the resting circumference (Fig. 4). The latter variations sometimes paralleled changes of end-expiratory IEP and ITP, but more often they occurred spontaneously (second panel in Fig. 4).

Intratracheal and intraesophageal pressures changed in parallel and no significant gradients were observed. However, zero reference points were not matched or verified and differential pressures were not recorded, so that we may not draw firm conclusions regarding IEP-ITP pressure gradients. However, it is of interest that occasionally, in each fetus, positive pressure swings were recorded from the intraesophageal balloon which could be mistakenly identified as "grunts" (Fig. 5). These "esophageal grunts" were not related to breathing since ITP and tracheal circumference did not change at the same time. "Esophageal grunts" were infrequent, irregular, and without fixed relationship to the periods of stimulation.

Amniotic fluid pressure did not change significantly either during periods of stimulation or during periods of spontaneous breathing.

\section{DISCUSSION}

Except for the exteriorized lower limb, the fetuses remained in utero throughout the experiments so that acute fluctuations of temperature cannot explain the results obtained. Similarly, $\mathrm{PaO}_{2}$, $\mathrm{PaCO}_{2}$, and arterial $\mathrm{pH}$ were normal and steady, and therefore not primary stimuli of the breathing patterns elicited. Since the fetuses were immersed in amniotic fluid and not otherwise manipulated during the trials, direct stimulation of touch, pain, proprioceptive, and other somatic receptors may be excluded.

\section{SOMATIC-RESPIRATORY REFLEX}

It is generally understood that suitable electrical stimulation of somatic nerves will change breathing and that included in the definition of "respiratory reflexes" are those afferent pathways that change or modify breathing patterns in response to or in association with a variety of physiologic or pathologic events (28). However, because most experiments on air-breathing subjects are conducted in the presence of rhythmically active respiratory center, a simple form of somatic-respiratory reflex (i.e., involuntary contraction of previously quiescent muscles resulting from somatic afferent stimulation) has not been described regarding the respiratory system. The fetus in utero seems to be an ideal subject for such investigation, since breathing is not a vital function and normally there are long periods of respiratory inactivity $(16,17)$. In this report the term "reflex" is used to characterize the breathing responses of the fetus which were either synchronous with slow frequency electrical stimulation of the sciatic nerve (i.e., where one stimulus pulse produced one inspiratory-expiratory cycle) or coincided with the period of stimulation. The designation "somatic-respiratory reflex" is given since the breathing movements were clearly generated by somatic afferent stimulation and easily interpreted in the absence of breathing movements before stimulation.

A respiratory response to sciatic nerve stimulation was first described by Jappelli (20), who demonstrated in the adult dog that respiratory rhythm could be modified by and even synchronized with slow frequency electrical stimulation of the nerve. Subsequently, Colle and Gybels (7) and Molina et al. (24) showed that stimulation of $\gamma$ and $\delta$ group $A$ and group $C$ fibers of peripheral nerves produced increased activity of the phrenic nerve of adult animals. The most extensive work in this area was carried out by Condorelli and his colleagues (8-11), who established that electrical (and also chemical) stimulation of peripheral nerves regularly produces polypnea. These workers indicated that the respiratory response may originate in receptors within skeletal muscle and that

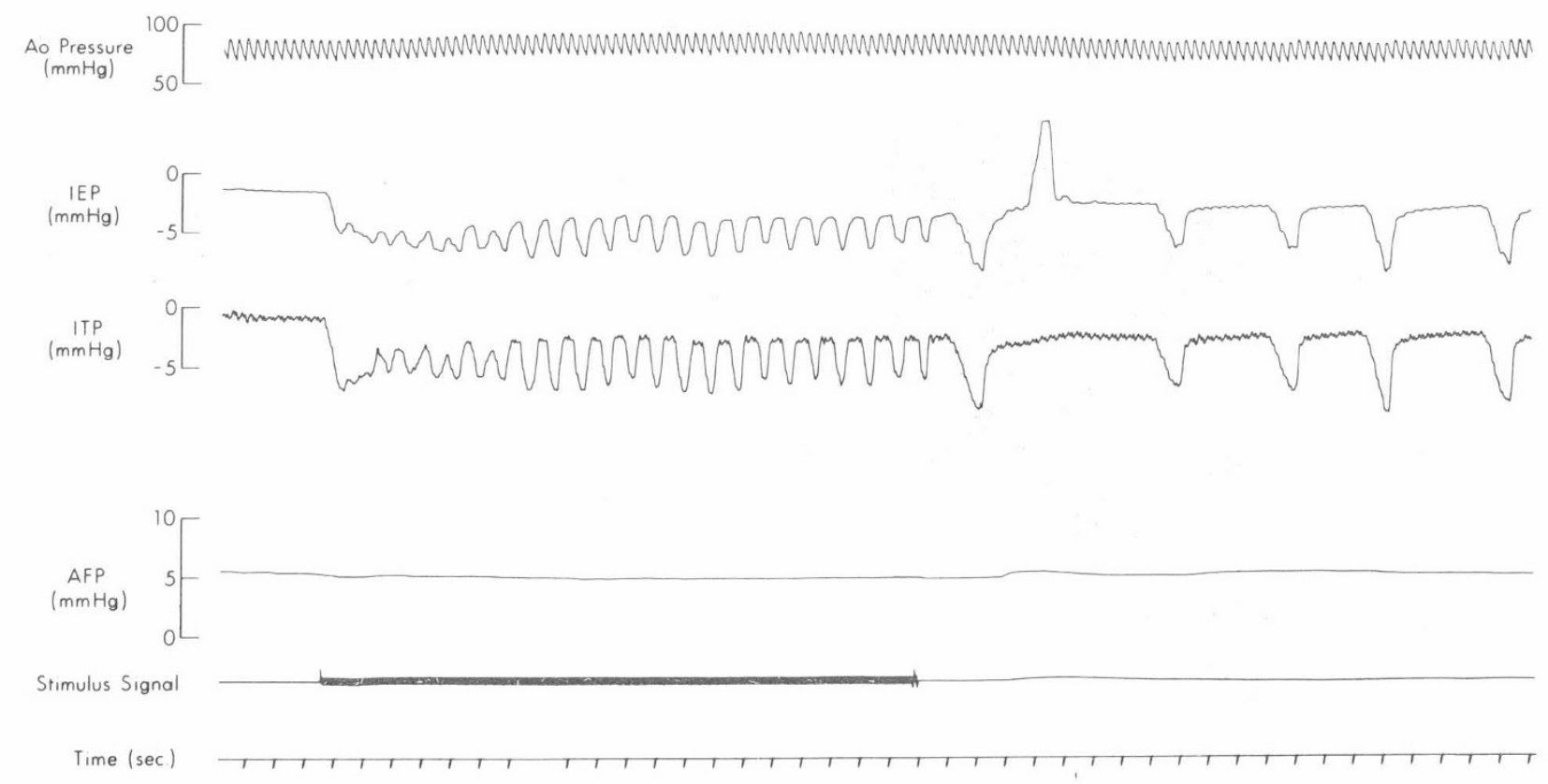

Fig. 5. Fetal aortic $(A o)$ pressure, intraesophageal pressure $(I E P)$, intratracheal pressure $(I T P)$, and amniotic fluid pressure $(A F P)$ during and after high frequency stimulation (15-V, 1.05-msec pulses at $66 \mathrm{cps}$ ). Spontaneous breathing continued for $45 \mathrm{~min}$. An "esophageal grunt" is shown in the IEP tracing. 
is clearly different from the well known respiratory responses to ortic and carotid chemoreceptor stimulation. Peripheral recepors have not been defined in our studies which, however, are onsonant with the possibility that muscle and also cutaneous eceptors may play a role.

The "reflex" response to low frequency stimuli in our experinents produced a complete inspiratory-expiratory cycle which was ndistinguishable from individual breathing cycles that were reorded during spontaneous regular breathing in other trials. Ilthough the afferent and efferent components of the reflex are ipparent, central mechanisms cannot be defined. However, certain leductions may be made: (I) When the quiescent (apneic) central espiratory neurones were aroused by somatic stimulation, inspiraory neurons were the first to respond. In no case was there an initial expiratory effort. (2) End-inspiration was followed by passive expiration in which end-expiratory IEP and ITP were more negative than the corresponding preinspiratory pressures. (The latter observation may be related to concurrent loss of fetal pulmonary fluid from the lung during breathing (26) and also possibly, to a change in lung compliance as the fluid enters pulmonary tissue.) (3) The progressive increase of end-inspiratory IEP and ITP with successive stimuli suggests recruitment of inspiratory neurones through sciatic nerve input until a maximal inspiratory drive is achieved.

With regard to the latter suggestion, it is important first to consider other alternative possibilities. These include $(I)$ the Hering-Breuer reflexes, the possible contribution of afferents from other viscera (e.g., carotid artery, aorta, heart, lungs, etc.), and the possible contribution of efferent cervical sympathetics. We feel that these may be excluded (18) as major factors in the present study, since we have shown, in parallel studies (13), that bilateral cervical vagotomy in the mature sheep fetus in utero does not alter either the reflex response or the onset of breathing response. (2) Another possibility is rapid progressive compensation to "loading" of the lung (29). Younes et al. (29) showed clearly that the progressive increase of inspiratory efforts that follows the imposition of an added load, including tracheal occlusion, is "totally" accounted for by concomitant (and relatively large) changes in blood gas tensions. For example, mean $\mathrm{PaO}_{2}$ fell by approximately $30 \mathrm{~mm} \mathrm{Hg}$ and $\mathrm{PaCO}_{2}$ increased by approximately $8 \mathrm{~mm} \mathrm{Hg}$ within $20 \mathrm{sec}$ after tracheal occlusion in their study. Thus this possibility may also be excluded, since $\mathrm{PaO}_{2}$ and $\mathrm{PaCO}_{2}$ of our fetuses were stable throughout the experiments, including those periods in which there was breathing activity. (3) The last is mediation by afferents from the chest wall (3). This possibility also seems of minor importance with regard to the progressive increase of inspiratory efforts during stimulation of the lamb fetus, since, as Younes et al. (29) pointed out, the direct mechanical effect of the load on the pathways of chest wall reflexes must be complete within the first loaded breath.

Thus our hypothesis regarding the progressive recruitment of central respiratory neurones during frequency stimulation of the sciatic nerve is summarized schematically in Figure 6, which is based on the "respiratory oscillator" model of Cohen $(5,6)$. Number $l$ in Figure 6 represents initial stimuli to which there was no apparent breathing response. With continued stimulation, number 2, expiratory-inspiratory $(E I)$ neuronal discharge increases to a critical level where activation of inspiratory-facilitatory $(I+)$ neurons produces a breathing movement $(I m)$. Recruitment of neurons continues until maximal discharge of $\mathrm{I}+$ results in maximal contraction of respiratory muscles for the given stimulation (number 3 ). At this point each stimulus pulse produces a single breathing effort. As stimulation continues (number 4 ) central inspiratory-inhibitory neurons $(I-$ and $E+)$ may continue to be recruited and their respective oscillatory loops become operative to the extent that they determine the rate of firing of the inspiratory neurons, i.e., the inherent rhythm of the central neurons (under background stimulation from the sciatic nerve) dominates. This scheme, which does not account for input from higher brain stem or cortical centers, is presented as a working hypothesis for the somatic-respiratory reflex of the fetus. Vagal

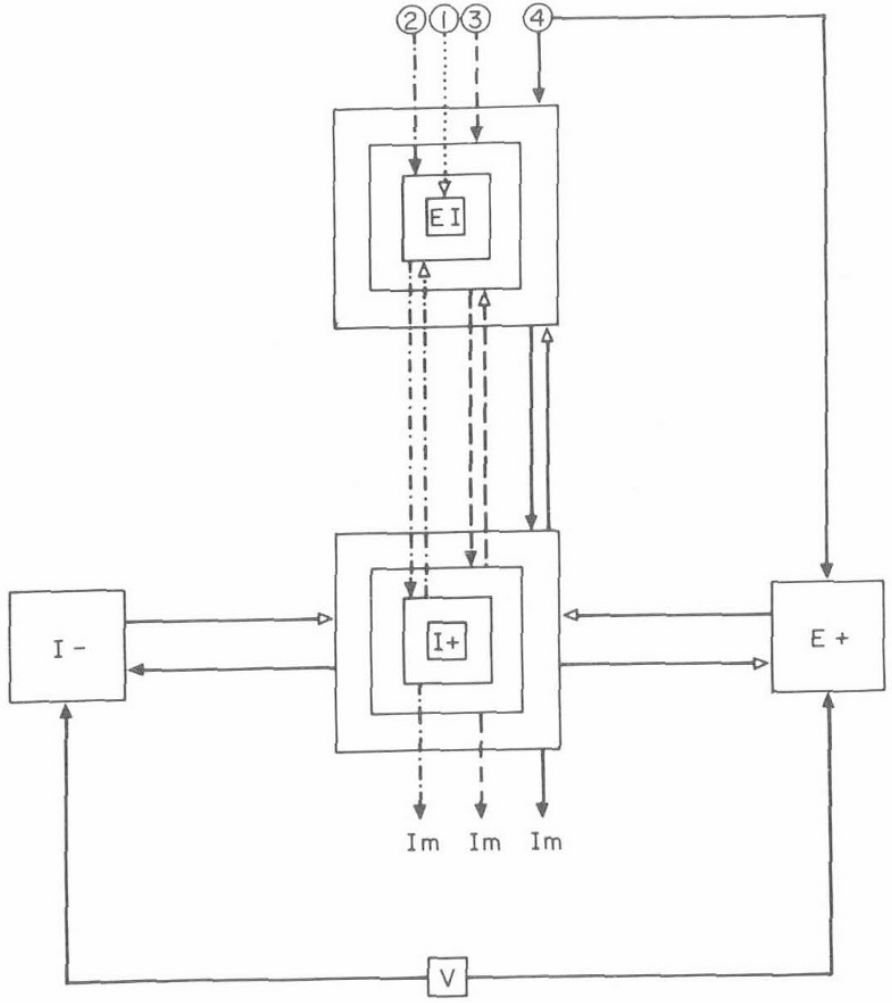

Fig. 6. Hypothetical scheme of the onset of regular breathing in the fetus based on the respiratory oscillator model of Cohen (4), modified by us. $E I$ : expiratory-inspiratory neurones; $I+$ : inspiratory-facilitatory system: $I m$ : inspiratory muscle contraction; inspiratory-inhibitory $(I-)$ and expiratory-facilitatory $(E+)$ neurones; $V$ : vagal afferents. Black arrowheads: facilitatory; white arrowheads: inhibitory. See text.

afferents from the lung are included in Figure 6, since the vagi may have played a permissive role (3), but did not mediate the reflex response (13), in the present study.

The "reflex" response was also induced with high frequency stimulation in which breathing movements stopped when stimulation was withdrawn. It may be deduced that the end stage of the somatic-respiratory reflex response (number 4 in Fig. 6) was achieved rapidly in these trials because of the barrage of impulses delivered to the central neurones.

\section{ONSET OF REGULAR BREATHING}

Spontaneous, regular breathing efforts continued for up to $2 \mathrm{hr}$ 30 min after stimulation was withdrawn in $67 \%$ of the trials. The response during the period of low frequency stimulation mimicked that of the "respiratory reflex." Applying our hypothesis to these findings, it is suggested that the "onset of regular breathing" response includes $(l)$ activation of central inspiratory neurons and related inhibitory oscillatory loops and (2) activation of centers (e.g., in the higher brainstem and cortex) that maintain respiratory frequency at levels which may be different than, but independent of stimulus frequency.

It is apparent that spontaneous breathing efforts as induced in our experiments, are different from the natural spontaneous breathing observed by Dawes et al. $(16,18)$, who reported rapid breathing movements, irregular both in rate and depth, associated with relatively large variations in fetal heart rate and blood pressure. They also observed that tactile stimulation of the nose or face was rarely associated with an inspiratory effort or a succession of efforts. In contrast, the spontaneous breathing induced by sciatic nerve stimulation was quite regular both in rate and depth and was not associated with large changes in heart rate and blood pressure. Thus it more closely resembles normal mature neonatal breathing and we may suggest that the fetus (at least up to 15 days before full term in the lamb) is set to initiate regular spontaneous 
breathing movements when adequately stimulated and that somatic sensory impulses can provide that stimulation. Extension of this line of research to younger fetuses should provide important information regarding the gestational age at which this set is established.

Spontaneous regular breathing has been induced in the lamb fetus by others. Dawes (15) showed that ligation of the umbilical cord alone, with its resultant asphyxial challenge to the fetus, may be followed by the establishment of normal breathing in the lamb. The effectiveness of cold as a respiratory stimulus at birth was well known to Barcroft (1), and Dawes (14) showed that application of cold alone can induce regular breathing in the fetus, whereas he reported that repeated tactile stimulations produced gasps but no sustained respiratory activity. In the present experiments sustained spontaneous breathing was generated in the lamb fetus in utero by somatic afferent stimulation in the absence of concomitant changes in body temperature, $\mathrm{pO}_{2}, \mathrm{pCO}_{2}$ and $\mathrm{pH}$. Since we did not stimulate single somatic afferent modalities in the present studies, we cannot state which fibers were the effective generators of breathing movement in the fetus. However, it may be relevant to note the recent report of Kattwinkel et al. (2.1) that regular "prophylactic" tactile stimulation of a newborn infant's extremity significantly reduces apneic episodes in "apnea of prematurity." Thus tactile stimulation, as well as stimulation of other sensory modalities in addition to cold, must continue to be regarded as potentially important respiratory stimulants. The experimental model reported here is well suited to further investigation along these lines, since fetal homeostasis is not altered during stimulation and subsequent response.

\section{CORRELATIVE OBSERVATIONS}

The effect of transmural pressure gradients on extrathoracic tracheal circumference, as determined from the mercury strain gauge, was apparent during each breathing cycle and in association with other fluctuations of ITP, wherein circumference increased as intraluminal pressure (ITP) increased and decreased as pressure decreased. (Extraluminal pressure probably approximated amniotic fluid pressure which was above atmospheric pressure and steady during most of the experiments.) In addition, there were rhythmic, slow frequency flucutations of end-expiratory tracheal circumference, upon which the breath-by-breath changes were superimposed. These were similar to rhythmic changes recorded in the air-breathing adult dog which were shown to be due to tonic vagal activity during eupnea (27). If we may assume that the rhythmic motion of the trachea is produced by rhythmic, tonic discharges from the vagi of the lamb fetus (as it is in the adult dog), it follows that this vagal activity is linked to activation of neurones of the respiratory center, since rhythmic tracheal motion was not observed in the absence of breathing in the fetus.

The ewes were maintained on $\mathrm{N}_{2} \mathrm{O}: \mathrm{O}_{2}, 3: 1-2: 1$ or less, throughout the experiments. Expectedly, these relatively low levels of $\mathrm{N}_{2} \mathrm{O}$ were even lower in the fetus, since the maternal-fetal gradient for $\mathrm{N}_{2} \mathrm{O}$ is about 2:1 (4). However, anesthesia was induced in the ewes with thiopental, $5 \mathrm{mg} / \mathrm{kg}$, and this seemed to depress respiratory responsivity in the fetus for about $60 \mathrm{~min}$, during which time breathing movements could not be elicited by sciatic stimulation and spontaneous breathing efforts were absent. Thiopental crosses the placenta and its concentration in umbilical venous blood is about half that of maternal venous blood approximately $10 \mathrm{~min}$ after it is administered to the mother (19). Thus, if the respiratory response to sciatic stimulation may be used as a criterion, it appears that thiopental may affect fetal breathing for relatively long periods at relatively low blood concentrations. This conclusion has been confirmed by other studies in our laboratory (13).

\section{SUMMARY}

The present studies were conducted on normal mature fetal lambs in utero. The breathing responses to electric stimulation of the afferent sciatic nerve were monitored and two types of response were observed. Stimulation and breathing responses were produced in the absence of any other alteration of fetal homeostasis.

The first type response might be termed "somatic-respiratory reflex": It is characterized by fetal breathing movements that coincided with the period of nonspecific somatic stimulation and, in $85 \%$ of those cases in which slow frequency stimuli were used, by breathing cycles that were synchronous with stimulus pulses.

These observations permitted a working hypothesis of the generation of breathing movements in the previously quiescent respiratory center, in which central respiratory neurons are recruited progressively during stimulation.

The second and more frequent response might be termed "onset of breathing": It is characterized by spontaneous fetal breathing movements that were sustained for up to $2 \mathrm{hr} 30 \mathrm{~min}$ after cessation of sciatic nerve stimulation. The spontaneous breathing resembled fetal breathing during asphyxia (cord ligation) and after cooling as reported by others, but was not like the reported naturally occurring irregular spontaneous breathing of the fetus in situ. Thus, nonspecific somatic stimulation alone may activate (according to our hypothesis) the central mechanisms that sustain spontaneous regular breathing in the mature fetus.

We have also presented evidence to suggest that rhythmic vagal tonus affecting airway caliber is linked to activation and maintenance of breathing in the fetus. It also appears that the fetus is more sensitive than the adult to the respiratory depressant effects of thiopental.

\section{REFERENCES AND NOTES}

1. Barcroft, J.: Researches on Prenatal Life, (Blackwell Scientific Publications, Oxford, 1946).

2. Boddy, K., and Mantell, C. D.: Observations of fetal breathing movements transmitted through the maternal abdominal wall. Lancet, II: 1219 (1972).

3. Campbell, E. J. M., Dickinson, C. J., and Howell, J. B. L.: The immediate effects of added loads on the inspiratory musculature of the rabbit. J. Physiol., 172 321 (1964).

4. Cohen, E. N., Paulson, W. J., Wall, J., and Elert, B.: Thiopental, curare, and nitrous oxide anesthesia for cesarean section with studies on placental transmission. Surg. Gynecol. Obstet., 97: 456 (1953).

5. Cohen, M. I.: How respiratory rhythm originates: Evidence from discharge patterns of brainstem respiratory neurones. In: Ciba Foundation HeringBreuer Centenary Symposium: Breathing, p. 125 (J. \& A. Churchill, London, 1970).

6. Cohen, M. I.: The genesis of respiratory rhythmicity. In: W. Umback and H. P. Koepchen: Central-Rhythmic Regulation, p. 15 (Hippokrates-Verla, Stuttgart, 1974).

7. Colle, J., and Gybels, J.: Etudes des reactions tensionnelles, respiratoires et corticales produites par l'excitation electrique des fibres afferentes d'un nerf somatique. Arch. Int. Physiol. Biochim., 65:547 (1957).

8. Condorelli, L.: I recettori vascolari periferici ad effetto respiratorio. Boll. Soc. Ital. Biol. Sper. 35: 1973 (1959).

9. Condorelli, L., Strano, A., Filocama, G.. Dagianti, A., Condorelli, S., and Bartolo, M.: Die fur chemische Reize empfindlichen Rezeptoren der peripheren Muskelgefasse und deren Wirkung auf die Atmung. Arch. Kreislaufforsch., 33: 72 (1960).

10. Condorelli, L., Strano, A., Filocamo, G., Dagianti, A., Condorelli, S., Bartolo, M., Chiavaro, A., and Patane, F.: Sitz und zuleiteride Bahneu der peripheren Gefass-Sensibilitat. Arch Kreislaufforsch., 35: 273 (1961).

11. Condorelli, L., Strano, A., Filocama, G., Dagianti, A., Condorelli, S., Bartolo, M., Lioy, F., and Visalli, M.: Untersuchungen uber die periphere Gefass-Sensibilitat-Uber den spezifischen Sitz der peripheren, mit KCN zeizbaren Gefassrezeptoren in den Muskelarteriolen. Arch. Kreislausfforsch.. 35: 265 (1961).

12. Condorelli, S., and Cosmi, E. V.: Cardiovascular-respiratory reflexes in the adult and fetal animal: Evidence for a reflex originating in skeletal muscle. In: Bases Fondamentales de l'Anesthesie et de la Reanimation Obstetricales, Tome 4, (Librairie Arnette Publ., Paris, 1972).

13. Condorelli, S., and Scarpelli, E. M.: Fetal breathing: Induction in utero and effects of vagotomy and barbiturates. J. Pediat. (in press).

14. Dawes, G. S.: Initiation and continuation of respiration. In: T. K. Oliver: Neonatal Respiratory Adaptation, (Public Health Service Publication No. 1432, Washington, D. C., 1966).

15. Dawes, G. S.: Fetal and Neonatal Physiology. (Year Book Medical Publishers, Inc., Chicago, 1968).

16. Dawes, G. S.: Revolutions and cyclical rhythms in prenatal life: Fetal respiratory movements rediscovered. Pediatrics 51: 965 (1973).

17. Dawes, G. S., Fox, H. E., Leduc, B. M., Liggins, G. C., and Richards, R. T.: Respiratory movements and paradoxical sleep in the foetal lamb. J. Physiol., 210: 47 (1970),

18. Dawes, G. S., Fox, H. E., Leduc, B. M., Liggins, G. C., and Richards, R. T.: 
Respiratory movements and rapid eye movement sleep in the foetal lamb. J. Physiol., 220: 119 (1972).

19. Finster, M., Mark, L. C., Morishima, H. O., Moya, F., Perel, J. M., James, L. S., and Dayton, P. G.: Plasma thiopental concentrations in the newborn following delivery under thiopental-nitrous oxide anesthesia. Amer. J. Obstet. Gynecol., 95: 621 (1966).

20. Jappelli, G.: La sincronizzazione dei movimenti respiratori con eccitamenti ritmici di nervi centripeti. Arch Fisiol., 3: 215 (1906).

21. Kattwinkel, J., Nearman, B. S., Fanaroff, A. A., Katona, P. G., and Klaus, M. H.: Apnea of prematurity. J. Pediat., 86: 588 (1975).

22. Khayutin, V. M.: Specific and non-specific responses of the vasomotor centre to impulses of spinal afferent fibres. Acta Physiol. Acad. Sci. (Hungary), 29: 131 (1966)

23. Merlet, C., Hoerter, J., Devilleneuve, C., and Tchobroutsky, C.: Mise en evidence de mouvements respiratoires chez la foetus d'agneau in utero au cours du dernier mois de la gestation. C. R. Acad. Sci. (Paris), 270: 2462 (1970).

24. Molina, A. F., Achard, O., and Wyss, O. A. M.: Respiratory and vasomotor responses to stimulation of afferent fibres in somatic nerves. Helv. Physiol. Pharmacol. Acta, 11: 1 (1953)

25. Scarpelli, E. M.: Perinatal respiration. In: E. M. Scarpelli and P. A. M. Auld: Pulmonary Physiology of the Fetus, Newborn and Child. (Lea \& Febiger, Philadelphia, 1975).
26. Scarpelli, E. M., Condorelli, S., and Cosmi, E. V.: Lamb fetal pulmonary fluid. I Validation and significance of method for determination of volume and volume change. Pediat. Res., 9: 190 (1975)

27. Scarpelli, E. M., Real, F. J. P.. and Rudolph. A. M.: Tracheal motion during eupnea, J. Appl Physiol., 20: 473 (1965)

28. Widdicombe, J. G.: Respiratory reflexes. In: W. O. Fenn and H. Rahn Handbook of Physiology, Section 3: Respiration, Volume I, p. 585 (American Physiological Society, Washington, D. C.. 1964).

29. Younes, M., Arkinstall, W., and Milic-Emili, J.: Mechanism of rapid ventilatory compensation to added elastic loads in cats. J. Appl. Physiol.. 35: 443 (1973).

30. Air Shield, Hatboro, Pa.

31. Grass Instruments, Quincy, Mass.

32. Dr. Scarpelli is a recipient of a Career Development Award from the National Heart and Lung Institute of the National Institutes of Health.

33. This research was supported by grants from the National Heart and Lung Institute, National Institutes of Health (HL 16137); New York Heart Association grant-in-aid; and Health Research Council of the City of New York (U-2091E).

34. Requests for reprints should be addressed to: E. M. Scarpelli, M. D., Ph.D. Department of Pediatrics, Albert Einstein College of Medicine, 1300 Morris Park Ave., Bronx, N. Y. 10461 (USA).

35. Accepted for publication July 14, 1975.

\title{
Serum Glutathione Reductase and Cystic Fibrosis
}

\author{
BURTON L. SHAPIRO, ${ }^{(18)}$ Q. T. SMITH, AND W. J. WARICK \\ Department of Oral Biology, School of Dentistry and Department of Pediatrics, University of Minnesota Health Sciences Center, \\ Minneapolis, Minnesota, USA
}

\section{Extract}

Serum glutathione reductase (NADPH:GSSG oxidoreductase, EC. 1.6.4.2 (GR)) has been examined in cystic fibrosis subjects (CF), obligate CF heterozygotes, and control subjects. Serum protein concentration was similar in the three groups. Regardless of the units used to express activity (milligrams of protein or milliliters of serum) or whether or not samples were dialyzed against water or phosphate buffer, mean serum $G R$ in $C F$ was greater than in control subjects $(P<\mathbf{0 . 0 0 2})$ in all series over several years. Under the above assay conditions no difference in serum GR between control subjects and carriers was detected. Calculated and assayed values of combined control and CF sera agreed as did expected and observed $50 \%$ activity in 1:2 sera dilutions in CF, control subjects, and carriers. Addition of FAD to incubation media did not effect enzyme activity in the three groups. Differences between CF and control subjects persisted after dialysis in membranes permitting passage of molecules of approximately $12,000 \mathrm{~mol}$ wt or less. These findings would tend to exclude the effect of extraneous serum factors in explaining the differences between $\mathrm{CF}$ and control subjects. The percentage of initial GR activity after four days storage $\left(0-4^{\circ}\right)$ was significantly greater in $\mathrm{CF}$ than in control subjects $(P<\mathbf{0 . 0 2 5})$. The effect of heparin on serum GR was recorded as the percentage of activity after incubation with heparin vs. activity in the standard assay for individual subjects. The effect of incubation with $5 \mu \mathrm{g} / \mathrm{ml}$ sparin on serum GR activity was greater in control subjects than in carriers $(P<0.0005)$ and $\mathbf{C F}(P<\mathbf{0 . 0 0 0 5})$. Mean serum $\mathbf{G R}$ activity in $\mathrm{CF}$ and carriers was unaffected by heparin, whereas mean activity in control subjects was decreased. In no control was the percentage of initial activity with heparin greater than the mean of $\mathrm{CF}$ and carrier groups. Only 3 of $20 \mathrm{CF}$ and 4 of 20 carrier individuals had percentages lower than the control mean. The $C F$ and carrier distributions were clearly different from the control distribution. Serum GR was determined in seven non-CF individuals with chronic obstructive pulmonary disease (COPD). Activity in the COPD was different from $C F$ and no different from control subjects. In none of these controls or COPD was serum GR as great as the CF mean. Serum GR in no CF was as low as the mean of control subjects or COPD. It is concluded that serum GR activity is greater in CF than in control subjects, carriers, and non-CF COPD subjects; that the difference in activity is not attributable to an extraneous serum factor, that the activity difference is not secondary to chronic respiratory disease; that in comparison with control subjects, GR from CF serum behaves differently after storage; and that serum GR from CF and carriers behaves differently from control GR in the presence of heparin.

\section{Speculation}

Abnormal activity of glutathione reductase may be fundamentally related to the pathogenesis of cystic fibrosis.

Despite numerous studies (7), the abnormal gene product in cystic fibrosis (CF) and hence its molecular basis is not yet known. The generally held view of CF pathogenesis concerns an abnormal transport of ions and other small molecules in exocrine tissues (8). Because enzyme systems of the pentose phosphate pathway are localized at sites of ion transport in salivary glands and other tissues $(11,12)$, we examined this system in CF. In red blood cells (RBC's) mean glucose-6-phosphate dehydrogenase (D-glucose6-phosphate:NADP oxidoreductase, EC. 1.1.1.49) activity was increased and the mean ratio of NADPH to $\mathrm{NADP}^{+}$was decreased in $\mathrm{CF}$ in comparison with age- and sex-matched controls 